\title{
Evaluation of genetic diversity in short duration cotton (Gossypium hirsutum L.)
}

\author{
AKTER T. ${ }^{1}$, ISLAM A. K. M. A. ${ }^{1 *}$ D, RASUL M. G. ${ }^{1}$, KUNDU S. ${ }^{2}$, KHALEQUZZAMAN $^{2}$ and AHMED J. U. ${ }^{3}$
}

\begin{abstract}
Background: Cotton (Gossypium hirsutum L.) is an important fiber crop in Bangladesh. Genetic diversity among the genotypes of a germplasm has a great importance for cotton breeding. An experiment was carried out at the experimental field of Cotton Research, Training and Seed Multiplication Farm, Sreepur, Gazipur during the cropping season of 2015-2016 with 100 genotypes to evaluate genetic diversity of cotton genotypes for short duration using field performance.

Results: The genotypes under study were grouped into ten clusters through multivariate analysis using GENSTAT-5. Cluster III contained maximum number of genotypes (16) while cluster $X$ contained the least number of genotypes (7). The inter cluster distances were larger than intra cluster distances in all cases suggesting wider genetic diversity among the genotypes of different clusters. The maximum and minimum inter cluster distances were observed between clusters II and V (10.78) and clusters VIII and IX (3.30), respectively. The results indicated diverse and close relationship among the genotypes of those clusters. Earliness index, single boll weight and days to boll opening showed the higher contribution to the genetic divergence among 19 characters.

Conclusion: Based on the results of genetic diversity and earliness index, the genotypes from cluster II could be used as parent in hybridization program for the development of short duration cotton variety.
\end{abstract}

Keywords: Cotton (Gossypium hirsutum L.), Genetic diverity, Earliness index, GOT, Yield

\section{Introduction}

Cotton is the most important natural fiber in the world for textile manufacture, accounting for about $50 \%$ of all fibers used in the textile industry (Fryxell 1992). It is the member of Malvaceae family and genus Gossypium. There are four species in the genus Gossypium - G. hirsutum L., G. barbadense L., G. arboreum L. and G. herbaceum L. - that were domesticated independently as source of textile fibre (Brubaker et al. 1999). Gossypium hirsutum L. is known as New World or upland cotton having tetraploid $(2 \mathrm{n}=4 \mathrm{x}=52)$ with the genome AADD (Brubaker et al. 1999). The place of origin of the genus is not known, however, the primary centres of diversity for the genus are west-central and southern Mexico (18 species), north-east Africa and Arabia (14 species) and Australia (17 species). Cotton is currently the leading fibre crop worldwide and is grown

\footnotetext{
* Correspondence: aminuljkkp@yahoo.com

${ }^{1}$ Department of Genetics and Plant Breeding, Bangabandhu Sheikh Mujibur

Rahman Agricultural University, Gazipur 1706, Bangladesh

Full list of author information is available at the end of the article
}

commercially in the temperate and tropical regions of more than 50 countries (Smith 1999). The major countries/regions of cotton production include USA, India, China, the Middle East and Australia.

Cotton is one of the important cash crops and the main raw materials of textile industry in Bangladesh. It is commonly known as 'Kapas tula' in Bangladesh. It is primarily cultivated for its lint, which is spun into yarn. Yarn is used for textile and several industrial uses. Raw cotton is also used for medical and surgical purposes. Around $4 \%-5 \%$ of the national requirement is fulfilled through the local production and remaining $95 \%-96 \%$ is fulfilled by importing raw cotton from USA (40\%), Commonwealth of Independent States (CIS) (35\%), Australia, Pakistan, South Africa and other cotton producing countries/regions (25\%) (Hamjah and Chowdhury 2014). The demand of textile products of cotton is increasing day by day due to increasing global population. Bangladesh's cotton consumption is expected to almost double by 2022, strongly retaining its position of world's second largest cotton importers (Anonymous 2016). 
In Bangladesh, cotton is generally grown as a rain fed crop in northern region and central region covering more than 32 districts out of 61 plain districts. Cotton is mostly cultivated as sole crop, but farmers are intended to grow three or more crops on the same land. Due to long duration (6-7 months) cotton can't be fixed in the exiting cropping pattern. Short duration cotton varieties will enhance production of cotton by enhancing acreage of cotton. The achievement of earliness is a basic breeding objective in upland cotton (Egamberdiev 1996; Braden and Smith 2004). Earliness in cotton can avoid yield losses due to seasonal threat of biotic and abiotic stresses and increase in economic return by reducing input cost like less input of fertilizer and irrigation and also less labor cost (Ali et al. 2003). So it is necessary to develop short duration cotton varieties to increase the interest of the farmer and cotton yield. Cotton earliness is a quantitative trait (Kassianenko et al. 2003). Various plant characteristics have been used to determine earliness in cotton. One node decrease in the first sympodial branch matures the cotton crop by approximately 4 to 7 days earlier (Ahmad et al. 2008; Baloch et al. 2014). Kairon and Singh (1996) determined that short duration cottons set fruits at the 4th or the 5th node while long duration varieties set them at the 8th or the 9th node. Several other researchers (Kerby et al. 1990; Kairon and Singh 1996; Baloch and Baloch 2004) have reported strong relationship between early maturity and lower sympodial branch node number and sympodial branch length.

Genetic diversity is the foundation for the development of new varieties. Better understanding of genetic diversity will help to select diverse parents for hybridization program. So there is a need to characterize available cotton genotypes using statistical tools and to utilize them in the breeding program. Cultivated cotton genotypes have narrow genetic base (Abdukarimov et al. 2003; McCarty et al. 2005). To broaden the genetic base through breeding program, the quantification of genetic divergence among available germplasm is prerequisite and a major goal in plant breeding. Information on genetic diversity within and among closely related genotypes is essential for a cogent use of germplasm (Govindaraj et al. 2015). Successful breeding program depends on the inclusive knowledge and understanding of the genetic diversity within and among the elite genetic materials of the existing germplasm. It enables plant breeder to identify promising genotypes as parental sources that will generate diverse populations for selection and for the development of improved cotton varieties. Keeping in view the above stated informations, the current study was aimed to assess genetic diversity of short duration cotton genotypes using various plant characteristics related to earliness in cotton.

\section{Materials and methods}

The experiment was carried out at the experimental field of Cotton Research, Training and Seed Multiplication Farm, Cotton Development Board (CDB), Sreepur, Gazipur during the cropping season 2015-2016. The healthy and disease-free seeds of 100 genotypes from the Gene Bank of CDB were used as experimental materials. Conventionally the time of cotton sowing in Bangladesh is from 15 July to 15 August, while harvest during December to January. The seeds were sown on 30th July 2015. The experiment was laid out in a Randomized Complete Block Design (RCBD) with three replications. The plot size was $12.15 \mathrm{~m}^{2}$. Row to row distance was $90 \mathrm{~cm}$ and plant to plant distance was 45 $\mathrm{cm}$. There was $90 \mathrm{~cm}$ gap between two replications. Whole amount of compost, $10 \%$ urea, $50 \%$ TSP and $25 \%$ MoP were applied as basal dose during land preparation and remaining fertilizer were applied at three installments. All intercultural practices were done according to CDB standard. Data were recorded on the following characters: days to emergence, node number bearing first sympodial branch (NFB), number of monopodial branches per plant, number of sympodial branches per plant, number of secondary fruiting branches per plant, leaf shape and color, plant height, days to squaring, days to flowering, days to first boll opening, number of flowers per plant, number of bolls per plant, single boll weight, first picking percentage, earliness index [calculated based on Bartlett (1973)], Ginning Out Turn (GOT \%) [(weight of lint/weight of seed)*100] and seed cotton yield per plant. The collected data were statistically analyzed. Analysis of variance was performed by using the help of general linear model procedure of computer package SAS (2000). Mean data for each character were subjected to multivariate analysis methods viz, Principal component analysis (PCA), Principal coordinate analysis (PCO), Canonical variate analysis (CVA) and Cluster analysis (CLSA) using GENSTAT-5. Principal components were computed from the correlation matrix and genotypic scores obtained for the first component and succeeding components with latent roots greater than unity (Mahalonobis 1936; Jeger et al. 1983). Inter-distances between genotypes were calculated by Principal coordinate analysis (Digby et al. 1989). The clustering was done using non-hierarchical classification. Computation of average intra-cluster distance for each cluster was calculated by taking possible $D^{2}$ values within the members of a cluster obtained from the PCO after the clusters are formed. The utilized formula was $\Sigma D^{2} / \mathrm{n}$, where $\Sigma D^{2}$ is the sum of distances between all possible combinations (n) of the genotypes included in a cluster. The square root of the average $D^{2}$ value represents the distance $(D)$ within cluster. 


\section{Results and discussion}

Cotton earliness is a quantitative trait which is mainly affected by environment and crop genotype (Kassianenko et al. 2003). Development of early maturing cotton varieties nowadays has become one of the important objectives of cotton breeders because of many reasons, such as short duration cotton cultivars can avoid yield losses that occur due to diseases, insect-pest (particularly bollworms) unfavorable and weather conditions (Singh 2004). The growing of early maturing cotton cultivars has an advantage of proper time for rotation of other crops allowing timely sowing of wheat in cotton-wheat-cotton cropping system in different countries (Ali et al. 2003). Late maturity of cotton also causes poor fiber quality (Salam et al. 1993). Moreover, the short duration cotton genotypes are economical regarding cost of production because early maturing cultivars evade from biotic and abiotic risks (Anderson et al. 1976; Anjum et al. 2001).

\section{Principal component analysis (PCA)}

The principal component analysis (PCA) provided eigen values and percent for 19 principal component axes in 100 cotton genotypes (Table 1). The results showed that the first four principal components accounted for $53.23 \%$ of the total variation among the 19 component axes of the total genotypes, whereas the

Table 1 Eigen values and percentage of variation for 19 principal component axes in 100 cotton genotypes

\begin{tabular}{llll}
\hline $\begin{array}{l}\text { Principal } \\
\text { component axes }\end{array}$ & $\begin{array}{l}\text { Eigen } \\
\text { values }\end{array}$ & $\begin{array}{l}\text { Percentage } \\
\text { variation }\end{array}$ & $\begin{array}{l}\text { Cumulative } \\
\text { percentage/\% }\end{array}$ \\
\hline A & 3.348 & 17.62 & 17.62 \\
B & 2.793 & 14.70 & 32.32 \\
C & 2.118 & 11.15 & 43.47 \\
D & 1.854 & 9.76 & 53.22 \\
E & 1.497 & 7.88 & 61.10 \\
F & 1.395 & 7.34 & 68.44 \\
G & 1.047 & 5.51 & 73.95 \\
H & 0.908 & 4.78 & 78.73 \\
I & 0.839 & 4.42 & 83.15 \\
J & 0.738 & 3.88 & 87.03 \\
K & 0.573 & 3.02 & 90.05 \\
L & 0.524 & 2.76 & 92.81 \\
M & 0.506 & 2.67 & 95.47 \\
N & 0.357 & 1.88 & 97.35 \\
O & 0.253 & 1.33 & 98.68 \\
P & 0.107 & 0.56 & 99.24 \\
Q & 0.104 & 0.55 & 99.79 \\
R & 0.038 & 0.20 & 99.99 \\
S & 0.002 & 0.01 & 100.00 \\
\hline
\end{tabular}

eigen values were found as $83.16 \%$ in the first seven component axes.

\section{Non-heirachical clustering}

Based on non-heirachical clustering, the 100 cotton genotypes were grouped into ten different clusters using co-variance matrix. Distribution of genotypes into different clusters is presented in Table 2. Cluster III contained maximum number of genotypes (16) while cluster IX contained 13 genotypes and cluster I, IV, VII contained ten genotypes, respectively (Table 2). Cluster $\mathrm{X}$ contained the least number of genotypes (seven). BC-0358 was grouped in cluster IV that was resulted in maximum yield with minimum days to boll opening in this study.

\section{Conical variate analysis (CVA)}

Intra and inter cluster distances $\left(D^{2}\right)$ values for 100 cotton genotypes grouped into 10 clusters are presented in Table 3. The more inter and intra cluster distances, the more variability among the genotypes between and within cluster, respectively, and vice versa. The results obtained from the present study indicated that the inter cluster distances were larger than intra cluster distances in all cases suggesting wider genetic diversity among the genotypes of different groups. The results are in agreement with Ali et al. (2012). The maximum inter cluster distance was observed between clusters II and V (10.78) followed by IV and V (9.37).

The maximum inter-cluster distance indicated that the genotypes in these clusters was far diverse than those of other clusters. The minimum inter-cluster distance was observed between clusters VIII and IX (3.30) indicating a close relationship among the genotypes of those clusters. The highest intra-cluster distance was found in cluster III (0.76) followed by cluster IX (0.63). The lowest intra-cluster distance was noticed for cluster $\mathrm{X}(0.16)$. These results revealed that the genotypes in cluster III were distantly related; on the other hand the genotypes in cluster $\mathrm{X}$ were closely related. The genotypes belonging to the distant clusters (II and V) could be used in hybridization program for obtaining a wide spectrum of variation among the segregates (Ali et al. 2012).

\section{Cluster mean for the characters}

The mean performances of 21 characters in six clusters are shown in Table 4. Most of the characters showed distinct difference among the clusters. In cluster I, it revealed the highest values for the character percent boll retention (74.25) and GOT (40.03\%). Cluster II produced the highest cluster mean for the character number of secondary fruiting branches per plant (5.62) and earliness index (0.90) and the lowest cluster mean for plant 
Table 2 Distribution of 100 cotton genotypes into ten clusters

\begin{tabular}{|c|c|c|}
\hline Clusters & Number of genotypes & Name of genotypes \\
\hline I & 10 & BC-0073, BC-0074, BC-0075, BC-0211, Win all 5, SR/L-17, SR/L-26, SR/L-30, SR/L-47, SR/L-55 \\
\hline$\|$ & 8 & BC-0113, BC-0292, BC-0293, BC-0319, BC-0332, BC-0335, BC-0349, BC-0353 \\
\hline III & 16 & $\begin{array}{l}\text { BC-0002, BC-0168, BC-0232, BC-0236, BC-0244, BC-0259, BC-0270, BC-0272, BC-0273, } \\
\text { BC-0281, BC-0283, BC-0289, BC-0291, BC-0303, BC-0337, BC-0372 }\end{array}$ \\
\hline IV & 10 & BC-0231, BC-0295, BC-0301, BC-3004, BC-0305, BC-0358, CB-9, CB-10, CB-12, CB-13 \\
\hline V & 9 & BC-0112, BC-0276, BC-0312, BC-0316, BC-0318, BC-0331, BC-0369, BC-0374, SR/L-42 \\
\hline $\mathrm{Vl}$ & 9 & BC-0333, BC-0354, BC-0355, BC-0359, BC-0362, BC-0366, BC-0378, BC-0383, CB-14 \\
\hline VII & 10 & BC-0111, BC-01 19, BC-0278, BC-0279, BC-0286, BC-0308, BC-0314, BC-0322, BC-0376, BC-0382 \\
\hline VIII & 8 & BC-0386, BC-0390, BC-0469, BC-0476, BC-0480, BC-0481, BC-0495, SR/L-51 \\
\hline IX & 13 & $\begin{array}{l}\text { BC-0037, BC-0306, BC-0470, BC-0475, BC-0482, BC-0483, BC-0492, BC-0496, BC-0501, } \\
\text { BC-0505, Win all 6, SR/L-36, SR/L-56 }\end{array}$ \\
\hline$x$ & 7 & BC-0294, BC-0375, BC-0493, BC-0497, BC-0502, SR-15, SR/L-14 \\
\hline
\end{tabular}

height $(115.88 \mathrm{~cm})$ and node number of bearing first sympodial branch (NFB) (6.53). Cluster III had the minimum cluster mean values observed for the character days to emergence (3.56 days). Cluster IV comprised the highest mean for seed cotton yield (2.12t/ha). Cluster $\mathbf{V}$ had the maximum mean values for the character number of flowers per plant (46.38) and number of bolls per plant (30.56).

In cluster VI, the highest mean value was found for number of plant at harvest (26.44) and the lowest mean value for the character days to boll opening (105.22 d). Cluster VII showed the highest mean for the character number of sympodial branches per plant (18.23). Cluster VIII had the maximum cluster mean value for the character germination percentage (95.83\%) and minimum cluster mean value for the character number of monopodial branches per plant (0.60). Cluster IX had the lowest cluster mean values for the character days to squaring (39.54 d), days to flowering (53.15 d) and single boll weight $(5.49 \mathrm{~g})$. None of the genotypes included in the cluster $\mathbf{X}$ having high mean values for any important characters.

\section{Contribution of characters towards divergence of the genotypes}

The characters contributing maximum to the divergence are given greater emphasis for deciding of the cluster for the purpose of further selection and the choice of parents for hybridization (Siddique et al. 2010). The relative contribution of 19 characters of the 100 genotypes towards the total divergence is presented in Table 5. Earliness index, single boll weight and days to boll opening had positive values in both vectors which indicated that they were the important component characters having higher contribution to the genetic divergence among genotypes studied. On the other hand, negative values in both vectors for number of plant at harvest, number of monopodial branch, number of secondary fruiting branch, days to flowering, days to squaring, percent first picks and seed cotton yield indicated the lowest contribution of these characters towards the divergence among 19 characters.

In Vector I (major axis of differentiation), important characters for genetic divergence were days to

Table 3 Average intra and inter cluster distances $\left(D^{2}\right)$ values for 100 cotton genotypes

\begin{tabular}{|c|c|c|c|c|c|c|c|c|c|c|}
\hline Cluster & 1 & $\|$ & III & IV & V & $\mathrm{Vl}$ & $\mathrm{VII}$ & VIII & IX & $x$ \\
\hline I & 0.324 & & & & & & & & & \\
\hline$\|$ & 8.281 & 0.229 & & & & & & & & \\
\hline III & 4.697 & 4.425 & 0.756 & & & & & & & \\
\hline IV & 6.442 & 5.950 & 3.955 & 0.285 & & & & & & \\
\hline V & 5.991 & 10.777 & 7.715 & 9.374 & 0.258 & & & & & \\
\hline $\mathrm{Vl}$ & 5.973 & 5.613 & 3.521 & 5.097 & 8.181 & 0.207 & & & & \\
\hline VII & 5.302 & 6.829 & 3.891 & 6.316 & 5.749 & 4.657 & 0.425 & & & \\
\hline VIII & 4.204 & 6.334 & 4.223 & 5.748 & 8.458 & 5.273 & 6.130 & 0.182 & & \\
\hline IX & 4.775 & 6.773 & 4.768 & 4.436 & 8.989 & 5.970 & 6.923 & 3.299 & 0.627 & \\
\hline$x$ & 3.927 & 8.504 & 5.212 & 6.119 & 5.215 & 5.984 & 4.953 & 4.924 & 5.047 & 0.157 \\
\hline
\end{tabular}


Table 4 Cluster mean for 19 characters in 100 cotton genotypes

\begin{tabular}{|c|c|c|c|c|c|c|c|c|c|c|}
\hline \multirow[t]{2}{*}{ Characters } & \multicolumn{10}{|l|}{ Clusters } \\
\hline & I & $\|$ & III & IV & V & $\mathrm{Vl}$ & VII & VIII & IX & $x$ \\
\hline Days to emergence & 3.80 & 3.87 & 3.56 & 4.00 & 3.67 & 3.89 & 3.60 & 4.00 & 3.92 & 4.00 \\
\hline Germination percentage/\% & 88.67 & 94.17 & 88.96 & 91.00 & 93.33 & 95.55 & 91.00 & 95.83 & 94.61 & 95.71 \\
\hline No. of plant at harvest & 24.05 & 22.81 & 24.81 & 24.90 & 24.06 & 26.44 & 24.30 & 25.19 & 23.15 & 22.14 \\
\hline Plant height /cm & 137.86 & 115.88 & 127.46 & 118.71 & 161.09 & 130.16 & 141.93 & 124.97 & 120.17 & 140.95 \\
\hline Days to squaring/d & 39.90 & 44.00 & 41.50 & 41.80 & 43.56 & 43.00 & 45.90 & 42.13 & 39.54 & 40.00 \\
\hline Days to flowering/d & 53.80 & 57.25 & 54.88 & 54.40 & 58.44 & 56.00 & 58.10 & 56.75 & 53.15 & 55.00 \\
\hline Days to boll opening/d & 128.20 & 110.87 & 114.37 & 109.50 & 118.33 & 105.22 & 112.40 & 127.87 & 124.62 & 119.86 \\
\hline Node no. bearing first sympodial branch (NFB) & 7.04 & 6.53 & 7.15 & 7.46 & 7.29 & 7.32 & 7.20 & 6.91 & 6.90 & 7.15 \\
\hline Number of monopodial branches & 0.83 & 1.02 & 0.87 & 0.70 & 0.98 & 0.81 & 0.87 & 0.60 & 0.82 & 0.77 \\
\hline Number of sympodial branches & 15.90 & 14.97 & 15.46 & 15.15 & 17.43 & 15.84 & 18.23 & 14.95 & 14.77 & 15.09 \\
\hline Number of secondary fruiting branches & 3.72 & 5.62 & 3.75 & 3.09 & 5.35 & 3.49 & 4.11 & 2.16 & 3.36 & 2.89 \\
\hline Number of flowers per plant & 40.44 & 36.27 & 37.92 & 37.40 & 46.38 & 37.76 & 40.49 & 34.23 & 35.74 & 36.71 \\
\hline Number of bolls per plant & 29.98 & 21.03 & 25.03 & 25.50 & 30.56 & 27.78 & 26.99 & 22.17 & 24.89 & 25.26 \\
\hline Percent boll retention/\% & 74.25 & 58.18 & 65.97 & 68.24 & 65.72 & 73.61 & 66.65 & 64.77 & 69.48 & 68.23 \\
\hline Single boll weight /g & 5.27 & 4.95 & 5.28 & 5.45 & 5.01 & 5.38 & 5.10 & 5.46 & 5.49 & 5.47 \\
\hline Percent first pick/\% & 66.83 & 72.74 & 70.67 & 57.88 & 61.34 & 71.85 & 69.71 & 68.01 & 56.11 & 55.77 \\
\hline GOT /\% & 40.03 & 35.39 & 37.79 & 36.47 & 38.33 & 36.78 & 39.19 & 39.30 & 39.08 & 39.11 \\
\hline Earliness Index & 0.87 & 0.90 & 0.88 & 0.81 & 0.84 & 0.89 & 0.87 & 0.88 & 0.82 & 0.81 \\
\hline Seed cotton yield /kg & 2.52 & 2.54 & 2.54 & 2.57 & 2.48 & 2.63 & 2.25 & 2.54 & 2.38 & 2.38 \\
\hline
\end{tabular}

Table 5 Relative contribution of 19 characters of cotton genotypes to the total divergence

\begin{tabular}{lll}
\hline Character & Vector-l & Vector-ll \\
\hline Days to emergence & 0.2235 & -0.0391 \\
Germination percentage & 0.1513 & -0.0913 \\
No. of plant at harvest & -0.1708 & -0.1328 \\
Plant height /cm & -0.2936 & 0.3080 \\
Days to squaring & -0.2927 & -0.2330 \\
Days to flowering & -0.2920 & -0.2100 \\
Days to boll opening & 0.0936 & 0.1022 \\
Node number of bearing first & -0.0700 & 0.1805 \\
sympodial branch (NFB) & & \\
Number of monopodial branch & -0.2194 & -0.1156 \\
Number of sympodial branch & -0.2800 & 0.1672 \\
Number of secondary fruiting branch & -0.2503 & -0.1036 \\
Number of flowers per plant & -0.3830 & 0.3010 \\
Number of bolls per plant & -0.2818 & 0.4324 \\
Percent boll retention & -0.0079 & 0.3460 \\
Single boll weight & 0.2131 & 0.0214 \\
Seed cotton yield & -0.2822 & -0.3036 \\
Percent first pick & -0.2711 & -0.2930 \\
Earliness index & 0.1140 & 0.2867 \\
GOT & 0.0194 & -0.1620 \\
\hline
\end{tabular}

emergence, germination percentage and GOT having positive vector values, while in Vector II, the second axis of differentiation, plant height, node number of bearing first sympodial branch (NFB), number of sympodial branches per plant, number of flowers per plant, number of bolls per plant and percent boll retention were important.

\section{Conclusion}

Genetic divergence of 100 upland cotton genotypes were investigated for short duration, yield related attributes and seed cotton yield using field performance. Principal component analysis showed that 10 components showed major role in total diversity and cluster analysis helped in the identification of superior genotypes for further utilization in breeding program. Cluster analysis showed that cluster III contained maximum number of genotypes (16) while cluster $\mathrm{X}$ contained the least number of genotypes(7). The maximum and minimum inter-cluster distances were observed between clusters II and V (10.78) and VIII and IX (3.30), respectively. Based on genetic diversity analysis, the genotypes from cluster II (BC 349), VI (BC 0378, CB 14) and IX (Win all 6) could be used as parents in hybridization program. 


\section{Acknowledgements}

The author acknowledges the support of the Cotton Development Board (CDB), Dhaka, Bangladesh for providing all research inputs and bearing the cost of field experiment. The authors would like to thank CDB authority for their support. The authors also would like to acknowledge their gratitude towards Bangabandhu Sheikh Mujibur Rahman Agricultural University authority for their support.

\section{Availability of data and materials}

The data generated and analyzed during the current study are available from the corresponding author(s) on reasonable request.

Data sharing not applicable for this article as all datasets were presented in the manuscript.

\section{Authors' contributions}

Akter T is a MS student who generated data of the current study and wrote the manuscript. Islam AKMA, Rasul MG and Ahmed JU are the member of her advisory committee who designed the experiments, analysed and interpreted the data and critically reviewed the manuscript. Kundu $\mathrm{S}$ provided germplasm of cotton and Khalequzzaman M provided facilities and monitored field experiment. All authors read and approved the final manuscript and have made substantive intellectual contributions to the manuscript.

\section{Ethics approval and consent to participate}

Not applicable.

\section{Consent for publication}

All co-authors has consent for submission of manuscript.

\section{Competing interests}

The authors declare that there is no competing interests.

\section{Author details}

'Department of Genetics and Plant Breeding, Bangabandhu Sheikh Mujibur Rahman Agricultural University, Gazipur 1706, Bangladesh. ${ }^{2}$ Cotton Development Board (CBD), Khamarbari, Dhaka, Bangladesh. ${ }^{3}$ Department of Crop Botany, Bangabandhu Sheikh Mujibur Rahman Agricultural University, Gazipur 1706, Bangladesh.

Received: 3 September 2018 Accepted: 5 December 2018

Published online: 11 January 2019

\section{References}

Abdukarimov AS, Djataev S, Abdukarimov I. Cotton research in Uzbekistan: elite varieties and future cotton breeding. Proceeding World Cotton Research Conference, Cape Town, South Africa. 9-13 March 2003: p. 5-15.

Ahmad SAE, Ahmad S, Ashraf MUH, et al. Assessment of yield related morhological measures for earliness in upland cotton (Gossypium hirsutum L. ). Pak J Bot. 2008;40(3):1201-7.

Ali CR, Arshad M, Khan MI, Fzal M. Study of earliness in commercial cotton (G. hirsutum L.) genotypes. J Res Sci. 2003;14(2):153-7.

Ali M, Mian MAK, Rasul MG, et al. Genetic diversity in local aromatic rice (Oryza sativa L.) genotypes. Bangladesh J Plant Breed Genet. 2012;25(2):33-40.

Anderson JM, Bridge RR, Heagler AM, Tupper GR. The economic impact of recently developed early season cotton strains on firm and regional cropping system and income. Proceed. Beltwide Cotton Prod Res Conf. Memphis: National Cotton Council of America; 1976. p. 98-100.

Anjum R, Soomro AR, Chang MA. Measurement of earliness in upland cotton. Pak J Biol Sci. 2001:4(4):462-3.

Anonymous. Increasing cotton production for sustainable RMG. Bangladesh Knitwear Manufacturers \& Exporters Association, The independent, 2016: http://m.theindependentbd.com/home/printnews/ 55950. Access on 23 Oct 2018.

Baloch MJ, Baloch QB. Plant characters in relation to earliness in cotton (Gossypium hirsutum). Proc Pakistan Acad Sci. 2004;41 (2):103-8.

Baloch MJ, Khan NU, Rajput MA, et al. Yield related morphological measures of short duration cotton genotypes. J Anim Plant Sci. 2014;24:1198-211.

Bartlett MS. Some examples of statistical methods of research in agriculture and applied botany. Int J R Stat Soc B. 1973;4:37-70.
Braden CA, Smith CW. Phenotypic measurements of fiber associations of nearlong staple upland cotton. Crop Sci. 2004;44:2032-7.

Brubaker CL, Bourland FM, Wendel JE. The origin and domestication of cotton. Chapter 1.1. In: Smith CW, Cothren JT, editors. Cotton: Origin, History, Technology, and Production. New York: Wiley; 1999. p. 3-31.

Digby P, Galway N, Lane P. GENSTAT 5: a second course. Oxford: Oxford Science Publications; 1989. p. 103-8.

Egamberdiev AE. Breeding for early maturing varieties of cotton. In: Proceedings of 55th plenary meeting of the ICAC, Tashkent, Uzbekistan; 1996. p. 9-12.

Fryxell PA. A revised taxonomic interpretation of Gossypium L. (Malvacea). Rheedae. 1992:2:108-68.

Govindaraj MM, Vetriventhan M, Srinivasan M. Importance of genetic diversity assessment in crop plants and its recent advances: an overview of its analytical perspectives. Genet Res Int. 2015:1-14. https://doi.org/10.1155/ 2015/431487.

Hamjah MA, Chowdhury MAK. Measuring climatic and hydrological effects on cash crop production and production forecasting in Bangladesh using ARIMAX model. Math Theory Model. 2014;4(6):138-52.

Jeger MI, Garethojies D, Griffiths E. Components of partial resistance of wheat seedling of Septoria nodorum. Euphytica. 1983;32:575-84.

Kairon MS, Singh W. Genetic diversity of short duration cottons. In: Proceedings of 55th Plenary Meeting of the ICAC, Tashkent, Uzbekistan; 1996. p. 5-9.

Kassianenko VA, Dragavtsev VA, Razorenov Gl, et al. Variability of cotton (Gossypium hirsutum L.) with regard to earliness. Genet Resour Crop Evol. 2003;50(2):157-63.

Kerby TA, Cassman KG, Keeley M. Genotypes and plant densities for narrow-row cotton systems. I. Height, nodes, earliness, and location of yield. Crop Sci. 1990;30(3):644-9.

Mahalonobis PC. On the generalized distance in statistics, vol. 2. India: Proceeding of National Institute of Sciences; 1936. p. 49-55.

McCarty JC, Jenkins JN, Wu J. Primitive accession derived germplasm by cultivar crosses as sources for cotton improvement. Crop Sci. 2005;44:1231-5.

Salam CA, Arshad M, Afzal M. Effect of picking dates on fiber character of different commercial cotton varieties of G. hirsutum L. Pak Cotton. 1993;37(2):67-74.

SAS Institute. The SAS system for Windows version 8. Cary: SAS Institute; 2000.

Siddique MA, Rashid ESMH, Khalequzzaman M, et al. Genetic diversity of local rainfed rice (Oryza sativa L.). Bangladesh J Plant Breed Genet. 2010;23(2):416. https://doi.org/10.3329/bjpbg.v23i2.9324.

Singh P. Cotton breeding. 2nd ed. New Delhi: Kalyani Pub; 2004. p. 118.

Smith WC. Production statistics. Chapter 3.1. In: Smith WC, Cothren JT, editors. Cotton: Origin, History, Technology and Production. New York: Wiley; 1999. p. 435-49.
Ready to submit your research? Choose BMC and benefit from:

- fast, convenient online submission

- thorough peer review by experienced researchers in your field

- rapid publication on acceptance

- support for research data, including large and complex data types

- gold Open Access which fosters wider collaboration and increased citations

- maximum visibility for your research: over $100 \mathrm{M}$ website views per year

At $\mathrm{BMC}$, research is always in progress.

Learn more biomedcentral.com/submissions 